\title{
Correction to: Determination of the Properties of the Rubber Mounted under the Agricultural Tractor Rollover Protective Structure Cabin Using a Hyperelastic Tensile Test and Finite Element Analysis
}

Ho-Sung Song ${ }^{1} \cdot$ Yu-Yong Kim ${ }^{1}$

Published online: 15 September 2020

(C) The Korean Society for Agricultural Machinery 2020

Correction to: Journal of Biosystems Engineering. https://doi.org/10.1007/s42853-020-00060-z

Due to an unfortunate oversight the acknowledgement section has been omitted. It should be read:

Acknowledgements This work was carried out with the support of "Research Program for Agricultural Science \& Technology Development (Project No. PJ013380)", National Institute of Agricultural Sciences, Rural Development Administration, Republic of Korea.

The online version of the original article can be found at https://doi.org/ $10.1007 / \mathrm{s} 42853-020-00060-\mathrm{Z}$

Yu-Yong Kim

kimkyu12@korea.kr

1 National Institute of Agricultural Sciences, Jeonju, Jeonbuk 54875, South Korea 